\title{
Experiment on Measurement of Interfacial Tension for Subsurface Conditions of Light Oil from Thailand
}

\author{
Jiramet Jiravivitpanya, Kreangkrai Maneeintr and Thitisak Boonpramote \\ Carbon Capture, Storage and Utilization Research Laboratory, Department of Mining and Petroleum Engineering, Faculty of Engineering, \\ Chulalongkorn University, Thailand
}

\begin{abstract}
One of enhanced oil recovery techniques to increase oil production is surfactant flooding. Surfactants are considered as effective chemical agents used in oilfield in Thailand. It is used to reduce the interfacial tension (IFT) of two fluids and to make them flow easier in the reservoir. In this study, Monoethanolamide (MEA) commonly used for carbon dioxide capture, is applied as a surfactant to reduce IFT between oil and brine. Therefore, the aim of this work is to investigate and measure the IFT based on the conditions of subsurface at the oilfield in Thailand. These parameters such as temperature, pressure, salinity as well as the concentration of surfactant are adjusted to investigate the effects on IFT reduction. From the results, it is reported that pressure from 1000 to 2000 psi and temperature varied from $70^{\circ} \mathrm{C}$ to $90^{\circ} \mathrm{C}$ can reduce IFT insignificantly. However, salinity and surfactant concentration are the main parameters that impact on the IFT reduction. It can greatly decrease IFT up to $87.13 \%$ for surfactant concentration and up to $74.06 \%$ for salinity. Finally, the results can be applied to use in the real field for enhanced oil production in Thailand.
\end{abstract}

\section{Introduction}

Nowadays, the world economic growth is developing continuously. Therefore, energy consumption is growing rapidly as well. Oil production needs to be enhanced to serve this increasing demand. Enhanced oil recovery (EOR) technology as tertiary recovery is getting more attention because of ineffective primary and secondary recoveries [1]. Surfactants are considered as one of the effective chemical flooding agents because it can significantly reduce the interfacial tension (IFT) between water and oil interfaces and increase values of both sweep efficiency and displacement efficiency, as well as decrease residual oil saturation [2].

However, there are some challenges that limit the prediction of efficient surfactant flood [3]. The effective in-situ IFT on surfactant flooding is controlled by several factors: (1) reservoirs conditions; (2) partitioning of surfactant between trapped oil and brine phases; (3) degree of surfactant dilution; and (4) surfactant adsorption onto the rock surface. These causes are difficult to know how IFT exactly changes under reservoir conditions, but there are researches [4] reporting some of concerning chemical parameters that effect on IFT. For this study, the research is focusing on the effect between aqueous surfactant solution and hydrocarbon phase such as pressure, temperature, salinity and surfactant concentration

The mechanism for IFT reduction in aqueous solution can be described in term of colloidal aggregates of surfactant molecules which are called micelles. When surfactant is put in aqueous solution, the dissolved surfactant molecules are dispersed on the interface as monomers and the surface free energy has been decreased. When the surfactant concentration is added more and the specific surfactant concentration called critical micelle concentration (CMC) is reached, the surfactant starts aggregating into micelles [1]. At above critical micelle concentration, the additional of surfactants will be insignificant on IFT reduction and also excess amount of surfactant in aqueous solution. The $\mathrm{CMC}$ values are used in process industry surfactant applications such as mineral processing to determinate the personal care food, to separate the different types of plastic and to bring the new surfactant into proper form because the greatest surfactant effect will be accomplished when significant micelles concentration is propose [5]. Therefore, the $\mathrm{CMC}$ is very important to concern when discussing in the formulation of micelles and applied in many process surfactant industries.

In this study, Monoethanolamide (MEA) is adopted as surfactant solution which is widely used in many chemical processes such as acid gas removal because it is cheap and can be easily found in the market. The molecular structure of MEA is presented in Fig. 1. From the figure, it is clear that MEA structure has 2 main parts, a hydrophilic part (hydroxyl and amino groups) which can dissolve in aqueous phase, and another part is called hydrophobic part (hydrocarbon chain) that can dissolve in oil phase Therefore, the aim of this work is to investigate and measure the IFT at oil-water interfaces based on the conditions of subsurface at the oilfield in Thailand. 
<smiles>NCCO</smiles>

Figure 1. Molecular structure of MEA

\section{Experiment}

\subsection{Chemicals}

Oil sample is obtained from the oilfield in the North of Thailand with the density of $0.84 \mathrm{~g} / \mathrm{cm}^{3}$. MEA is purchased from Sigma-Aldrich mixed with simulated brine. Brine is prepared from distilled water and sodium chloride purchased from Ajax at various salinity depending on the sources in the oilfield.

\subsection{Equipment}

The interfacial tension meter in Fig. 2 (Model 700, Vinci Technology) used for measuring the interfacial tension (IFT) between liquid-liquid and liquid-gas interface has chamber volume of $1 \times 10^{-5} \mathrm{~m}^{3}$. The maximum working pressure and temperature are $69 \mathrm{MPa}$ (or 10,000 psi) and $180^{\circ} \mathrm{C}$ (or $350^{\circ} \mathrm{F}$ ), respectively. Then, a computer connected with camera will analyze the IFT value and also record the shape of the drop with Drop Analysis Software (DAS) provided by Vinci Technology.

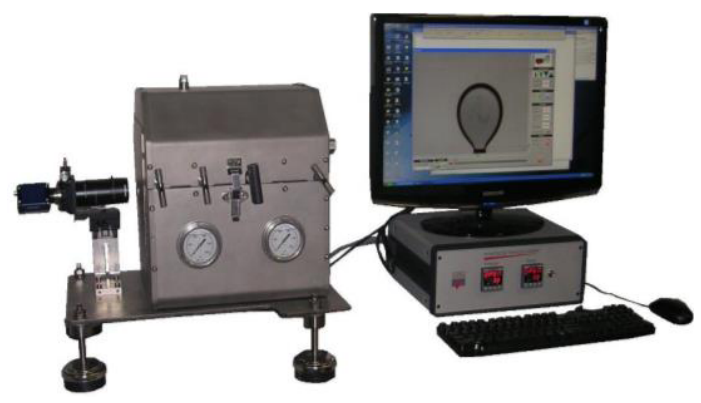

Figure 2. Interfacial tension apparatus (Model 700, Vinci Technology)

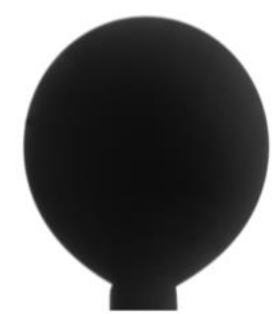

Figure 3. Rising oil drop

\subsection{Experimental procedures}

The IFT 700 is set up to run the experiment. Before measuring the IFT, software requires the density of oil and surfactant solution. The density can be measured by density meter. The running process would be cleaned by using acetone and distilled water. Then, both oil sample and surfactant solution are fed to sample cylinder and heated up to the desired temperature. The surfactant solution as well as the oil would be injected to the chamber of IFT 700 at designed pressure. The camera connected to computer will detect the generated drop which is created by calibrated capillary in the chamber as presented in Fig. 3. The results will then be recorded by integrated software.

The parameters will be varied to measure IFT as shown in Table 1. First, the surfactant concentrations are prepared at $0.5,1.0,2.0$ and $4.0 \mathrm{wt} \%$. Second, the salinity is set at 7,500,10,000,15,000 and 17,500 ppm. Then, the temperature is also varied at 70,80 and $90^{\circ} \mathrm{C}$. Lastly, pressure would be tested for 3 values which are 1,000, $1,500,2,000 \mathrm{psi}$. The operating conditions for this study are presented in Table 1.

Table 1 Operating conditions for IFT measurement

\begin{tabular}{|l|c|}
\hline \multicolumn{1}{|c|}{ Parameters } & Operating conditions \\
\hline Type of surfactant & Monoethanolamine (MEA) \\
\hline Solution concentration $\left(\mathrm{wt}^{\circ} \mathrm{)}\right)$ & $0.0,0.5,1.0,2.0,4.0$ \\
\hline Temperature $\left({ }^{\circ} \mathrm{C}\right)$ & 70,80 and 90 \\
\hline Pressure $(\mathrm{psi})$ & $1,0001,500$ and 2,000 \\
\hline Salinity $(\mathrm{ppm})$ & $\begin{array}{c}0,7,500,10,000,15,000, \\
\text { and } 17,500\end{array}$ \\
\hline
\end{tabular}

\section{Results and discussion}

\subsection{Effect of pressure on IFT}

As shown in Fig. 4, when pressure changes, the IFT just changes a small extent. Basically pressure has more effect on gas but the liquid phase system has intermolecular force higher than gas phase system. Therefore, pressure has less effect on IFT with liquidliquid system. According to D.W. Green and G.P. Willhite [6], it shows that the pressure on phase behavior at constant temperature would have a small effect on IFT.

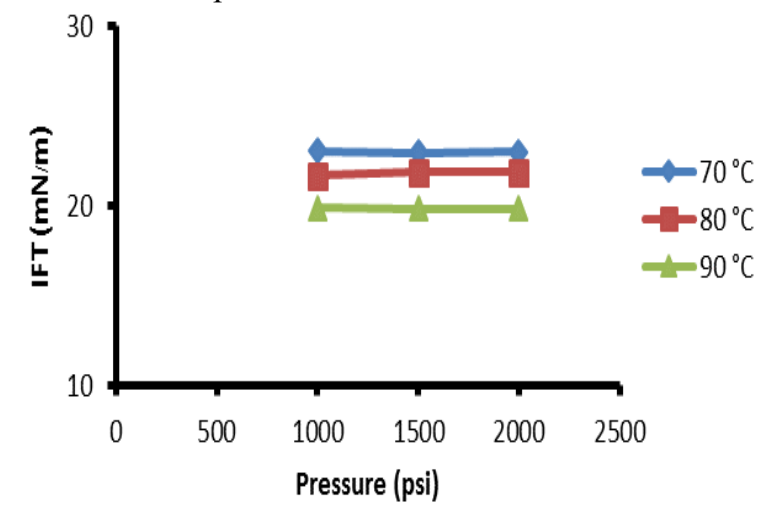

Figure 4. Effect of pressure on the IFT at MEA concentration $0.05 \mathrm{wt} \%$ and salinity $15,000 \mathrm{ppm}$

\subsection{Effect of temperature on IFT}

The range of temperature in this study will cover the temperature of the conditions in the oilfield from $70^{\circ} \mathrm{C}$ to $90^{\circ} \mathrm{C}$. Fig. 5 and 6 show the effect of temperature and salinity for the solutions without and with surfactant, respectively. Both cases have an opposite effect of temperature on IFT in that IFT will be decreased as temperature increases. When the temperature is higher, 
the free energy between oil and solution would reduce thus resulting in the enhanced mobility of oil and water and also decreasing the IFT [7]. One more reason is that the increment of temperature can effect on surfactant solution because of the weakening of intermolecular forces at the oil-water interface [8]. From Fig. 5, the results indicate that the percentage of IFT changes in case of $15,000 \mathrm{ppm}$ of salinity without surfactant, temperature from $70^{\circ} \mathrm{C}$ to $80^{\circ} \mathrm{C}$ and $80^{\circ} \mathrm{C}$ to $90^{\circ} \mathrm{C}$ are $2.0 \%$ and $0.7 \%$ respectively. Also, in Fig. 6 the rate of IFT change in case of $15,000 \mathrm{ppm}$ with $1 \mathrm{wt} . \% \mathrm{MEA}$, temperature from $70^{\circ} \mathrm{C}$ to $80^{\circ} \mathrm{C}$ and $80^{\circ} \mathrm{C}$ to $90^{\circ} \mathrm{C}$ are $12.2 \%$ and $7.2 \%$ respectively. The temperature from $80^{\circ} \mathrm{C}$ to $90^{\circ} \mathrm{C}$ can describe that interface between oil and water is less space for occupying of surfactant. Therefore, the rate of declining IFT trends to be decreased.

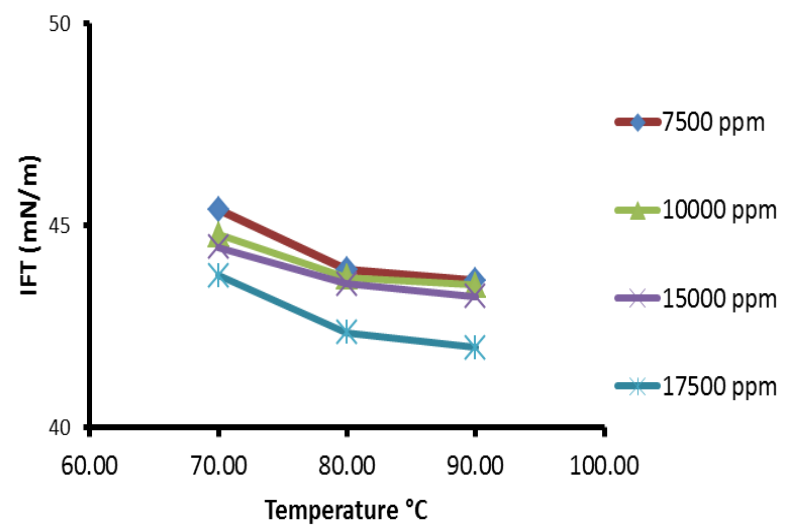

Figure 5. Effect of temperature on the IFT at various salinities without surfactant and pressure at 1,500 psi

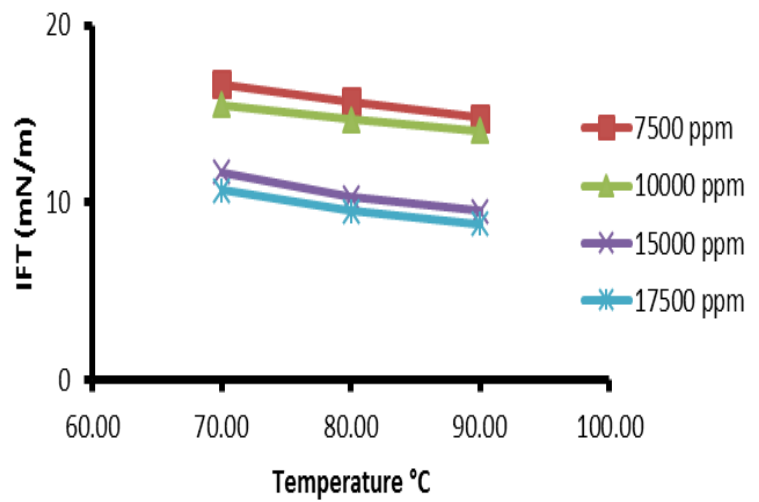

Figure 6. Effect of temperature on the IFT at MEA concentration $1 \mathrm{wt} . \%$ and pressure at $1,500 \mathrm{psi}$

\subsection{Effect of salinity on IFT}

The water produced from the oilfield is composed mainly of the various ions in the reservoir. Most of them are sodium and chloride ions accounting for $96 \%$. Fig. 7 indicates the IFT trends to be lower as the salinity of brine increases. The reason for these changes is that the ionic solution pushes the surfactant to oil-water interface. Besides, the incremental of salinity concentration can enhance the absorption of surfactant (MEA) at the oilwater interface that causes the lowering of IFT [9]. However, for the salinity ranging from 15,000 to 17,500 ppm, the IFT slightly decreases. Particularly, for case of concentration at $4.00 \mathrm{wt} \%$, salinity has less significant on IFT reduction because high salt changes try to drive amount of in-situ surfactant to the oil-water interface, but the space in there is not sufficient for occupying by surfactant.

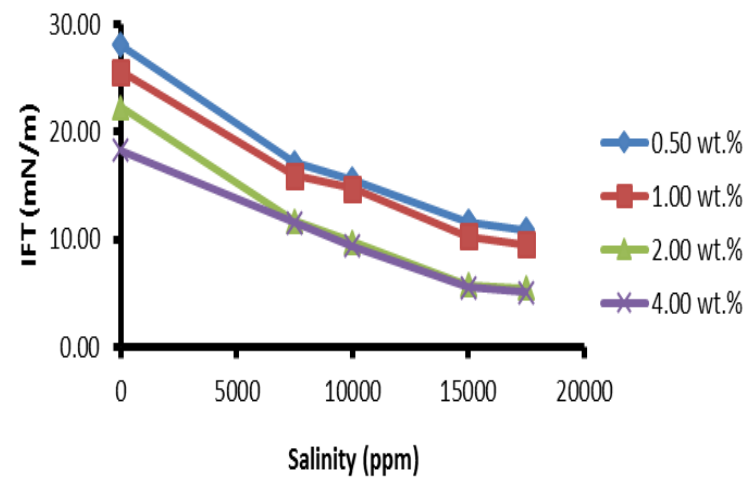

Figure 7. Effect of Salinity of brine on the IFT at temperature at $80^{\circ} \mathrm{C}$ and pressure at $1,500 \mathrm{psi}$

\subsection{Effect of surfactant concentration on IFT}

As shown in Fig. 8, the effect of surfactant concentration is presented at various brine concentrations with 1,500 psi and $80^{\circ} \mathrm{C}$. The result shows that at any salinity concentration, the reduction in IFT in all cases is caused by chemical characteristic of MEA. There are two parts of MEA's molecular structure. One part is called hydrophilic part (hydroxyl and amino groups) which can dissolve in aqueous phase, and another part is called hydrophobic part (hydrocarbon chain) that can dissolve in oil phase. The surface is covered by the surfactants molecules as monomers and the surface free energy (surface tension) has decreased. Thus, an increase in surfactant concentration can dissolve more both oil and water thus making the reduction of IFT corresponding to $\mathrm{Wu}$ et al [10]. In addition, the low concentration varied from $0 \%$ wt. to $2.0 \%$ wt can greatly decrease the IFT more than $74 \%$. Nevertheless, when the surfactant concentration is higher than $2.0 \mathrm{wt} \%$, the IFT value becomes stable or a little bit change in interfacial tension. The reason is that the surfactant is added in aqueous solution excessively resulting in the surfactant aggregating into micelles which is called critical micelle concentration (CMC). Consequently, the amount of MEA is difficult to possess in oil-water interface.

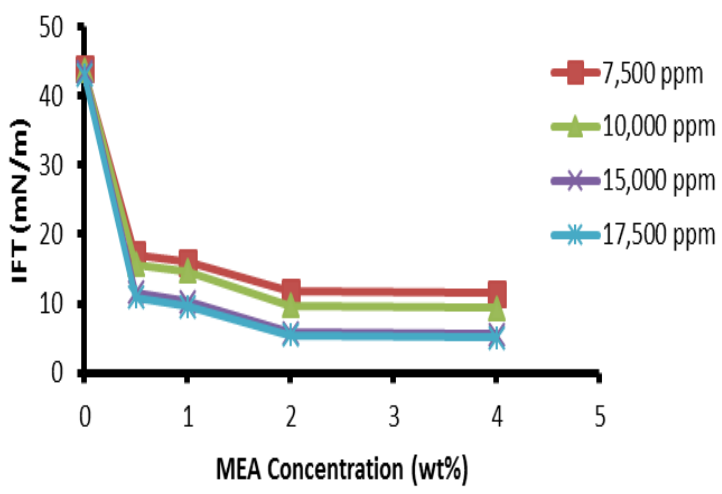

Figure 8. Effect of surfactant concentration on the IFT temperature at $80^{\circ} \mathrm{C}$ and pressure at $1,500 \mathrm{psi}$ 


\section{Summary}

Chemical enhanced oil recovery techniques are used to increase oil production by using surfactant flooding. Surfactants are considered as effective chemical agents used in oilfield in Thailand. It is used to reduce the interfacial tension of two fluids and to make them flow easier in the reservoir. In this study, Monoethanolamide (MEA) commonly is applied as a surfactant to reduce IFT between oil and brine based on the conditions at the subsurface from the oilfield in Thailand. From this research, the results report the IFT data at various conditions as well as the effects of each parameter such as pressure, temperature, surfactant concentration and salinity on IFT reduction at reservoir conditions in Thailand. Pressure ranging from $1,000 \mathrm{psi}$ to $2,000 \mathrm{psi}$ at constant temperature has less significant effect on IFT reduction and can be ignored. Also, temperature has less effect on IFT reduction and the rate of declining IFT trends to be decreased with the increase of temperature. However, the IFT can be reduced by increasing salinity from 0 to $15,000 \mathrm{ppm}$ accounting up to $74.06 \%$. Also, IFT becomes more stable when salinity is higher than $15,000 \mathrm{ppm}$. The IFT can greatly decrease up to $87.13 \%$ as surfactant concentration increases from $0 \%$ to $2 \mathrm{wt} \%$, but it will be relatively constant at the concentration higher $2.0 \mathrm{wt} \%$. These investigated effects of each parameter will be useful to understand and used as fundamental data to apply for oil recovery with reservoir conditions in the oilfield in Thailand.

\section{Acknowledgement}

The authors would like to thank the 90th Anniversary of Chulalongkorn University, Rachadapisak Sompote Fund and Graduate School Thesis Grant and Overseas Academic Presentation Scholarship for Graduate Students, Chulalongkorn University for financial support. Moreover, Defense Energy Department at Fang district,
Chiang Mai, Thailand is acknowledged for light oil sample.

\section{References}

1. J. J. Sheng, in: Modern Chemical Enhanced Oil Recovery: theory and practice, Gulf Professional Publishing (2011)

2. M. Ali Ahmadi, Y. Arabsahebi, S. Reza Shadizadeh, S. Shokrollahzadeh Behbahani. Preliminary evaluation of mulberry leaf-derived surfactant on interfacial tension in an oil-aqueous system: EOR application, Fuel 117, 749-755 (2014)

3. Y. P. Zhang, S.G. Sayegh and S. Huang, Effect of Oil/Brine Ratio on Interfacial Tension in Surfactant Flooding, Canadian International Petroleum Conference, 12-14 June, Calgary, Alberta, Canada, (2007)

4. J. Buckley and T. Fan, Crude Oil/Brine Interfacial tension, The Society of Core Analysts Symposium 48, (2005)

5. L. Schramm, N. Stasiuk and D. Gerrard Marangoni, Surfactants and their applications, Annual Reports Section 'C' (Physical Chemistry) 99, 10 (2003).

6. D.W. Green, G.P. Willhite, Enhanced oil recovery SPE Textbook Series 6, USA, 262 (1998)

7. X. Wei, in: Experimental Investigation of Dynamic Interfacial Interactions at Reservoir Conditions, Louisiana State University and Agricultural and Mechanical College, (2005).

8. W. Karnanda, M.S. Benzagouta, A. AlQuraishi and M.M. Amro: Arab J. Geosci. 6, 3535 (2013)

9. A.J. Prosser and E.I. Franses: Colloids and Surfaces A: Physicochemical and Engineering Aspects 178, 1 (2001).

10. Z. Wu, X. Yue, T. Cheng, J. Yu and H. Yang: Journal of Petroleum Exploration and Production Technology 4, 9 (2014). 